\title{
PERSPECTIVES
}

\section{Adapting active case-finding for TB during the COVID-19 pandemic in Yogyakarta, Indonesia}

\author{
G. Chan, ${ }^{1}$ R. Triasih,,${ }^{2,3}$ B. Nababan, ${ }^{3}$ P. du Cros, ${ }^{1}$ N. Wilks, ${ }^{1}$ S. Main, ${ }^{1}$ G. K. L. Huang, ${ }^{1}$ D. Lin, ${ }^{1}$ S. M. \\ Graham, $, 1,4,5$ S. S. Majumdar, ${ }^{1,4}$ M. Bakker, ${ }^{6}$ A. Khan, ${ }^{7}$ F. A. Khan, ${ }^{7}$ B. Dwihardiani ${ }^{3}$
}

http://dx.doi.org/10.5588/pha.20.0071

The COVID-19 pandemic and response measures, including lockdowns and the reorientation of health services, have disrupted essential health services for other diseases, including TB, HIV and malaria. For TB, reductions in case detection due to the COVID-19 pandemic are projected to result in increased TB transmission, morbidity and mortality. Active case-finding (ACF) for TB using community-based approaches is a potential strategy to offset reductions in TB detection by obviating the need for patients to seek care at a health facility. A number of approaches can be used to conduct TB ACF safely and screen designated target populations while managing the risks of SARS-CoV-2 transmission for staff, individuals and the community. We present a framework of options for and experience of adapting TB ACF services in response to the challenges of COVID-19 in our programme in Yogyakarta, Indonesia. Key changes have included revised prioritisation of target populations focusing on household contacts, reducing case-finding throughput, implementation of additional infection control measures and precautions, and integration of COVID-19 screening among those being screened for TB. Our approach could inform other programmes seeking to adapt TB ACF services to mitigate the negative impact of COVID-19 on TB case detection.

n early March 2020, Indonesia reported its first case of COVID-19, the disease caused by the novel virus SARS-CoV-2. As with many low- and middle-income countries, there was concern that high rates of disease and mortality would result and exceed the capacity of the healthcare system. By the end of March, Indonesia had initiated strategies to reduce transmission of SARSCoV-2, including lockdowns involving the cessation of public gatherings and restriction of people's movement beyond their village of residence. ${ }^{1}$ Reorientation of health services and resources to respond to COVID-19 was also commenced. ${ }^{1}$ These COVID-19 response measures have implications for essential health services and disease control programmes, including TB.

$\mathrm{TB}$ is a major cause of morbidity and mortality in Indonesia, which reported the second highest number of new TB cases in 2019. ${ }^{2}$ Indonesia also has the third largest gap between TB incidence and case notification, suggesting that many individuals with TB are left undiagnosed. ${ }^{2}$ COVID-19 has further impacted Indonesia's TB response due to the redirection of medical resources to the COVID-19 response, and due to potential suppression of care seeking for TB. ${ }^{2}$

In Yogyakarta, Indonesia, where only limited active case-finding (ACF) has previously been implemented, we initiated a TB ACF programme in late 2019 as described in Table 1. However, programme activities were suspended in March 2020 when COVID-19 cases were detected in Yogyakarta, as there was limited guidance on whether TB ACF was considered essential and on how to operationalise TB ACF during the COVID-19 pandemic. ${ }^{3}$ Furthermore, TB ACF activities can put patients, community members and health staff at increased risk for SARS-CoV-2 infection due to the increased person-to-person interaction. However, delays in TB detection can lead to increased transmission in the community, more severe disease in individuals and increased TB-related mortality.

In this paper, we discuss the potential value of conducting TB ACF during the COVID-19 pandemic to mitigate disruption of routine TB services. We then present our experience of planning and implementing adapted TB ACF services in Yogyakarta for consideration by other programmes wishing to conduct TB ACF in the context of COVID-19.

\section{Ethics}

No ethics approval was required, as this study pertained only to policy and design of TB services and did not involve human research subjects.

\section{THE IMPORTANCE OF TB ACTIVE CASE- FINDING DURING THE COVID-19 PANDEMIC}

Globally, TB is the leading cause of death from infectious diseases and an estimated 10 million people fall ill with TB each year. ${ }^{2}$ There is currently insufficient progress to achieve the WHO global targets of a 95\% reduction in $\mathrm{TB}$ deaths and a 90\% reduction in new cases between 2015 and 2035.2,4 The detection gap between notified and incident TB cases in 2019 was estimated at 2.9 million cases. ${ }^{2}$ Optimising and scaling up TB ACF is needed to address the detection gap and reduce TB prevalence by preventing ongoing transmission from undiagnosed cases. ${ }^{4,5}$ However, TB ACF services are often insufficient and are not prioritised in high-burden settings. ${ }^{5}$

The COVID-19 pandemic has caused significant health, social and economic upheaval. ${ }^{6}$ Many coun-
AFFILIATIONS

1 Burnet Institute, Melbourne, VIC, Australia

2 Department of Paediatrics, Faculty of Medicine, Public Health and Nursing, Universitas Gadjah Mada/ Dr. Sardjito Hospital, Yogyakarta, Indonesia

3 Centre of Tropical Medicine, Faculty of Medicine, Public Health and Nursing, Universitas Gadjah Mada, Yogyakarta, Indonesia

4 Department of Paediatrics, University of Melbourne and Murdoch Children's Research Institute,

Melbourne, VIC, Australia

5 International Union

Against Tuberculosis and Lung Disease, Paris, France

6 KIT Royal Tropical Institute, Amsterdam, The Netherlands

7 STOP TB Partnership, Geneva, Switzerland

8 McGill International TB Centre, Centre for Outcomes Research \& Evaluation, Research Institute of the McGill University Health Centre, Montreal, QC, Canada

CORRESPONDENCE Correspondence to: Geoff Chan, Burnet Institute, 85 Commercial Road, Melbourne, VIC 3004 Australia.email: geoff.chan@ burnet.edu.au

KEY WORDS

contact investigation; screening; diagnosis

Received 16 November 2020 Accepted 16 March 2021

PHA 2021; 11(2): 41-49 e-ISSN 2220-8372 
tries have implemented lockdowns that restrict peoples' movement and the operation of businesses and services to reduce SARS-CoV-2 transmission. Modelling shows that the pandemic and restrictions to manage it will negatively impact TB control by reducing TB detection and treatment, resulting in increased transmission and mortality. ${ }^{7,8}$ In the first half of 2020, a 25$30 \%$ reduction in TB notifications has already been observed in the four highest burden countries. ${ }^{2}$ Furthermore, in a recent survey, 78\% of Global Fund-supported TB programmes reported being disrupted by COVID-19. ${ }^{9}$

Several factors in the COVID-19 pandemic may decrease TB detection: reduced care-seeking due to lockdowns and concerns of transmission risk at health facilities, diversion of resources from $\mathrm{TB}$ to the COVID-19 response, and strategies to reduce health facility usage. Passive case-finding (PCF) is particularly vulnerable to disruption, as it usually relies on individuals to seek medical attention at health facilities after developing TB symptoms. This is especially concerning because persons who are symptomatic are more likely to have severe disease, are at risk of poorer outcomes if undiagnosed, and are more likely to transmit TB to others. ${ }^{5,10}$

TB ACF aims to detect TB prior to or soon after onset of symptoms, when disease is less extensive and less contagious. It is typically undertaken in populations at increased risk of TB such as household contacts, people living with HIV, migrant workers or in the general population in settings with high TB transmission. It can also be delivered in the community to reach individuals who may not seek timely care at a health facility. ${ }^{5}$

Community-based TB ACF approaches could overcome barriers to health facility-based TB diagnosis by investigating persons who are symptomatic or unwell, but have not sought care or are unable to access care due to COVID-19 and associated restrictions. With the protracted nature of the COVID-19 pandemic, TB ACF should be considered to reduce the TB mortality and morbidity that result from suppressed case detection. ${ }^{8}$ In Yogyakarta, we developed a framework to guide the adaptation of our programme's activities so that TB ACF could be implemented during the COVID-19 pandemic.

\section{CONSIDERATIONS IN ADAPTING TB ACTIVE CASE-FINDING DURING THE COVID-19 PANDEMIC}

There are a number of important considerations in determining whether and how to adapt TB ACF during the COVID-19 pandemic. The setting-specific situation in relation to COVID-19 transmission and the health system response to COVID-19 are critical in determining whether TB ACF can be conducted. We propose a checklist of essential criteria to consider: 1) Can TB ACF be conducted without diverting resources needed for the COVID-19 response? 2) Can it be conducted safely for staff and patients? 3) Is there government and stakeholder consensus on whether and how to proceed? 4) Will it be acceptable for individuals and communities?
ACKNOWLEDGEMENTS The authors would like thank the Stop TB Partnership which has funded our TB active case-finding project in Yogyakarta, Indonesia, through the TB Reach funding mechanism; the Dinas Kesehatan for Yogyakarta Province and for Kota Yogyakarta and Kulon Progo Districts. Conflict of interests: none declared.

TABLE 1 Summary of the original plans for a TB ACF program in Yogyakarta, Indonesia

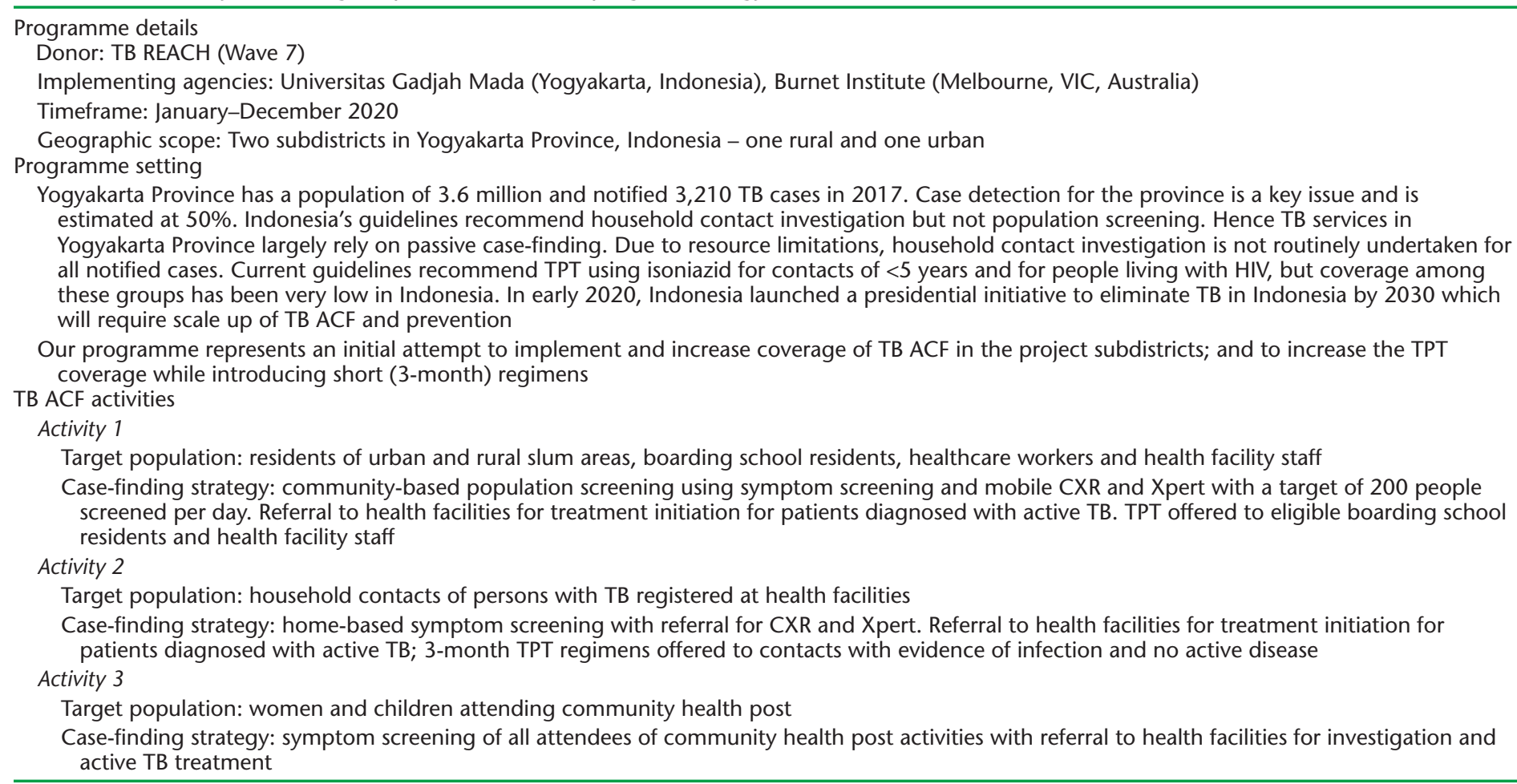

$\mathrm{ACF}=$ active case-finding; $\mathrm{TPT}=\mathrm{TB}$ preventive therapy; $\mathrm{CXR}=$ chest $\mathrm{X}$-ray. 
TABLE 2 Options for TB active case-finding during the COVID-19 pandemic

\begin{tabular}{|c|c|c|c|c|c|}
\hline ACF option & Target & Description & Pros & Cons & $\begin{array}{l}\text { Possible COVID-19 } \\
\text { integration }\end{array}$ \\
\hline $\begin{array}{l}\text { High-risk } \\
\text { community } \\
\text { symptom } \\
\text { screening by } \\
\text { CHWs }\end{array}$ & $\begin{array}{l}\text { Symptomatic and } \\
\text { acutely unwell } \\
\text { individuals in } \\
\text { the community }\end{array}$ & $\begin{array}{l}\text { CHWs (kader) routinely } \\
\text { screen for symptomatic } \\
\text { persons in their } \\
\text { catchment areas and } \\
\text { notify the ACF team to } \\
\text { investigate any } \\
\text { presumptive cases } \\
\text { Questions: } \\
\text { Should people with } \\
\text { presumptive TB be } \\
\text { referred to health } \\
\text { facility for further } \\
\text { investigation or should } \\
\text { a team visit the } \\
\text { patients in the } \\
\text { community with Xpert } \\
\text { and/or mobile CXR? }\end{array}$ & $\begin{array}{l}\text { May help to detect } \\
\text { symptomatic cases in } \\
\text { communities and areas } \\
\text { where/when other ACF } \\
\text { activities are not being } \\
\text { conducted } \\
\text { Opportunity to engage } \\
\text { community and } \\
\text { transfer knowledge for } \\
\text { COVID-19 and TB } \\
\text { Opportunity to increase } \\
\text { community testing for } \\
\text { COVID-19 in } \\
\text { symptomatic patients }\end{array}$ & $\begin{array}{l}\text { Relies on an active } \\
\text { network of CHWs with } \\
\text { supervision and } \\
\text { support } \\
\text { Sensitivity and specificity } \\
\text { of symptom screening } \\
\text { could vary widely } \\
\text { Potential high demand } \\
\text { on clinical services but } \\
\text { low yield of } \\
\text { bacteriologically } \\
\text { confirmed cases if } \\
\text { symptom screening } \\
\text { criteria are oriented } \\
\text { towards high sensitivity } \\
\text { Challenging to protect all } \\
\text { CHWs from risk of } \\
\text { SARS-CoV-2 and TB } \\
\text { infection }\end{array}$ & $\begin{array}{l}\text { Community education } \\
\text { and awareness } \\
\text { Screening for COVID-19 } \\
\text { based on symptoms } \\
\text { and history } \\
\text { Monitoring and support } \\
\text { of persons in home } \\
\text { isolation }\end{array}$ \\
\hline $\begin{array}{l}\text { Contact } \\
\text { investigation }\end{array}$ & $\begin{array}{l}\text { Close contacts of } \\
\text { notified TB } \\
\text { cases }\end{array}$ & $\begin{array}{l}\text { Investigation of } \\
\text { household contacts } \\
\text { and/or other close } \\
\text { contacts by health } \\
\text { workers using } \\
\text { appropriate personal } \\
\text { protective equipment } \\
\text { and algorithms that } \\
\text { enable physical } \\
\text { distancing and reduced } \\
\text { patient contact with } \\
\text { health services } \\
\text { Questions: } \\
\text { Should TB infection } \\
\text { testing (e.g., tuberculin } \\
\text { skin test) be done to } \\
\text { test for infection as it } \\
\text { requires extra visits? } \\
\text { Should TB preventive } \\
\text { treatment be provided? }\end{array}$ & $\begin{array}{l}\text { Feasible with small team } \\
\text { and infection } \\
\text { prevention and control } \\
\text { Focuses on screening a } \\
\text { high-risk group with a } \\
\text { known exposure, so } \\
\text { potential high yield } \\
\text { Contact investigation } \\
\text { already recommended } \\
\text { in NTP guidelines } \\
\text { Overlap in procedures, } \\
\text { training with COVID-19 } \\
\text { response }\end{array}$ & $\begin{array}{l}\text { Limited throughput: } \\
\text { contacts of different } \\
\text { index cases may be } \\
\text { dispersed } \\
\text { geographically } \\
\text { Limited number of index } \\
\text { cases in some areas, } \\
\text { especially if relying on } \\
\text { passive case-finding } \\
\text { that is disrupted by } \\
\text { COVID-19 } \\
\text { Possible risk of SARS- } \\
\text { CoV-2 infection for staff } \\
\text { if they encounter a } \\
\text { person with COVID-19 } \\
\text { inside a household } \\
\text { (staff will be donning } \\
\text { and doffing personal } \\
\text { protective equipment } \\
\text { frequently) }\end{array}$ & $\begin{array}{l}\text { Community education } \\
\text { and awareness } \\
\text { Screening for COVID-19 } \\
\text { Specimen collection for } \\
\text { COVID-19 testing } \\
\text { COVID-19 contact } \\
\text { investigation }\end{array}$ \\
\hline $\begin{array}{l}\text { Community-based } \\
\text { ACF with mobile } \\
\text { CXR }\end{array}$ & $\begin{array}{l}\text { Symptomatic and } \\
\text { asymptomatic } \\
\text { cases in target } \\
\text { community } \\
\text { populations }\end{array}$ & $\begin{array}{l}\text { Using multiple methods } \\
\text { of physical distancing } \\
\text { and infection control to } \\
\text { conduct ACF using a } \\
\text { mobile screening } \\
\text { service with CXR to set } \\
\text { up temporary } \\
\text { community-based ACF } \\
\text { sites }\end{array}$ & $\begin{array}{l}\text { Screening with CXR will } \\
\text { aid in the detection of } \\
\text { patients who may be } \\
\text { asymptomatic } \\
\text { Rationalises the use of } \\
\text { Xpert testing } \\
\text { Screen more people in } \\
\text { one occasion } \\
\text { Opportunity to expand } \\
\text { testing for COVID-19 in } \\
\text { symptomatic and } \\
\text { asymptomatic cases }\end{array}$ & $\begin{array}{l}\text { As above with COVID } \\
\text { risks } \\
\text { Possible low uptake if } \\
\text { there are community } \\
\text { concerns about ACF } \\
\text { services and crowding } \\
\text { at ACF sites }\end{array}$ & $\begin{array}{l}\text { Community education } \\
\text { and awareness } \\
\text { Screening for COVID-19 } \\
\text { Specimen collection for } \\
\text { COVID-19 testing } \\
\text { COVID-19 contact } \\
\text { investigation }\end{array}$ \\
\hline
\end{tabular}


TABLE 2 (continued)

\begin{tabular}{|c|c|c|c|c|c|}
\hline ACF option & Target & Description & Pros & Cons & $\begin{array}{c}\text { Possible COVID-19 } \\
\text { integration }\end{array}$ \\
\hline $\begin{array}{l}\text { Community-based } \\
\text { ACF using Xpert } \\
\text { testing of sputum } \\
\text { for all }\end{array}$ & $\begin{array}{l}\text { Symptomatic and } \\
\text { asymptomatic } \\
\text { cases in the } \\
\text { community }\end{array}$ & $\begin{array}{l}\text { Small team conducts } \\
\text { case-finding in the } \\
\text { community by going } \\
\text { door-to-door and } \\
\text { collecting sputum } \\
\text { samples from all } \\
\text { individuals screened } \\
\text { Samples could also be } \\
\text { used for viral testing } \\
\text { Sample collection can be } \\
\text { done outdoors and } \\
\text { with distancing }\end{array}$ & $\begin{array}{l}\text { Decentralisation of TB } \\
\text { diagnostic services } \\
\text { Can be implemented } \\
\text { with social distancing } \\
\text { maintained } \\
\text { Opportunity to } \\
\text { strengthen infection } \\
\text { control procedures? } \\
\text { Opportunity to expand } \\
\text { testing for COVID-19 in } \\
\text { symptomatic and } \\
\text { at-risk }\end{array}$ & $\begin{array}{l}\text { Greater resources and } \\
\text { time needed for the } \\
\text { programme to screen } \\
\text { door-to-door: reduced } \\
\text { throughput } \\
\text { Need adequate supplies } \\
\text { Expense of more Xpert } \\
\text { testing } \\
\text { Potentially lower } \\
\text { sensitivity and yield } \\
\text { than CXR screening } \\
\text { - will miss some } \\
\text { Xpert-negative TB } \\
\text { cases that X-ray will } \\
\text { help diagnose } \\
\text { In some settings, being } \\
\text { diagnosed with TB is a } \\
\text { potential disincentive } \\
\text { for COVID testing due } \\
\text { to stigma } \\
\text { Possible risk of SARS- } \\
\text { CoV-2 infection for staff } \\
\text { if screening a person } \\
\text { with COVID-19 } \\
\text { Infection risks for TB and } \\
\text { SARS-CoV-2 when } \\
\text { collecting samples }\end{array}$ & $\begin{array}{l}\text { Community education } \\
\text { and awareness } \\
\text { Screening for COVID-19 } \\
\text { Specimen collection for } \\
\text { COVID-19 testing } \\
\text { COVID-19 contact } \\
\text { investigation }\end{array}$ \\
\hline $\begin{array}{l}\text { Using ACF teams to } \\
\text { identify high-risk } \\
\text { patients and } \\
\text { transfer them to a } \\
\text { facility with X-ray }\end{array}$ & $\begin{array}{l}\text { Symptomatic } \\
\text { cases in the } \\
\text { community }\end{array}$ & $\begin{array}{l}\text { Screening in community } \\
\text { by ACF teams with } \\
\text { subsequent transport } \\
\text { of high-risk patients to } \\
\text { an X-ray facility }\end{array}$ & $\begin{array}{l}\text { Assists patients in } \\
\text { overcoming barriers in } \\
\text { reaching care } \\
\text { Avoids extensive } \\
\text { modification that } \\
\text { would be required for } \\
\text { safe operation of } \\
\text { mobile X-ray services }\end{array}$ & $\begin{array}{l}\text { Requires regular cleaning } \\
\text { of vehicle between } \\
\text { each patient - } \\
\text { depending on vehicle } \\
\text { seat materials may not } \\
\text { be able to easily clean } \\
\text { for fomites } \\
\text { Requires personal } \\
\text { protective equipment } \\
\text { and use of masks by } \\
\text { patients and staff } \\
\text { during transport in the } \\
\text { vehicle } \\
\text { Expensive due to the time } \\
\text { required to transport } \\
\text { relatively few patients }\end{array}$ & $\begin{array}{l}\text { Community education } \\
\text { and awareness } \\
\text { Screening for COVID-19 } \\
\text { Specimen collection for } \\
\text { COVID-19 testing } \\
\text { COVID-19 contact } \\
\text { investigation }\end{array}$ \\
\hline
\end{tabular}

$\mathrm{ACF}=$ active case-finding; $\mathrm{CHW}=$ community health worker; NTP = National TB Programme; $\mathrm{CXR}=$ chest $\mathrm{X}$-ray

The WHO transmission scenarios for SARS-CoV-2 and associated priorities for the health systems response can guide the selection of a TB ACF approach in different phases of the outbreak. ${ }^{11}$ The load imposed on the health system by demand for prevention, diagnosis and management of COVID-19 will also be crucial to judge whether TB ACF will divert resources needed for the COVID-19 response. Critically, there should be repeated appraisal against these essential criteria as the COVID-19 situation changes.

Decisions on how to conduct TB ACF should be guided by priorities for case-finding and reducing TB transmission. Examples of priorities include reaching populations who are under-served, those whose access to care has been most disrupted, or those who are at highest risk of TB infection and disease. These priorities will shape which populations are screened and the methods used to screen them. Table 2 presents the range of options our programme considered for conducting TB ACF in Yogyakarta.

\section{Integration of COVID-19 activities into TB ACF services}

TB ACF can integrate activities that support the COVID-19 response, including community engagement and education; screen- ing, referral and testing for COVID-19; implementation of infection control measures for both diseases; and conducting contact investigation from known COVID-19 cases. These can be readily integrated into TB ACF processes, for example, by adding COVID-19 screening questions into TB screening interviews or collecting specimens for COVID-19 testing. Strategies such as specimen pooling could also reduce laboratory time and costs involved in scaling up COVID-19 testing. ${ }^{12}$ Integration of COVID-19 testing into TB ACF could also contribute to surveillance in contexts where the extent of community transmission is not well understood. Training for TB ACF staff on COVID-19 infection control could be offered to other health managers, health workers and community cadres to strengthen capacity more broadly. Finally, contact investigation teams for TB could be used to also investigate COVID-19 contacts.

\section{What are the challenges in implementing TB ACF safely?} If implementing TB ACF, an important question is how to conduct ACF activities safely for persons affected by TB and staff. Existing practices for community screening for TB often create 
TABLE 3 Risks for TB active case-finding and options to manage them

Risk/challenge
persons who may have COVID-19 and/or TB
- Training on infection control, adaptation of existing infection control standard operating procedures to incorporate risk of exposure to both TB and SARS-CoV-2

- Triage and management of persons with presumptive COVID-19 prior to TB screening

- Telehealth to conduct initial screening interviews

- Maintain physical distance when interviewing persons (preferably outdoors or in a well-ventilated area)

- Provide those presenting to services with cloth or surgical masks

- PPE when examining patients (standard, contact and airborne precautions)

- Additional PPE when conducting aerosol-generating procedures, including sputum collection and laboratory examination

- Regular COVID-19 testing of ACF staff

- Healthcare workers undertaking testing will need to have adequate knowledge of both diseases and the consequences of a positive test for either (or both) to provide consistent and adequate responses to questions from community members

Risk of increasing person-to-person transmission - Focus on conducting ACF with the household as the unit and locus of intervention: screening of of SARS-CoV-2 and TB during case-finding (ACF can create large gatherings of people who come to be screened and wait in close quarters

household contacts or community screening by going door-to-door

- Conduct initial screening of contacts by phone

- Reduce throughput of screening - fewer persons attend at a time, enact physical distancing while waiting

Symptoms for TB and for COVID-19 are likely to - Maintain physical distancing between persons

overlap, meaning that screening for COVID-19 • Disinfection of surfaces and equipment after each person seen

may expose people to the risk of TB patients - Educate community about hand hygiene and provide surgical masks for persons to wear and vice versa)

- Environmental cleaning of waiting areas

- Adequate ventilation: natural or mechanical ventilation

- Triage, separation and management of patients with suspected COVID-19 prior to TB investigation

Risk of SARS-CoV-2 and TB transmission when taking CXR in vans

- X-ray procedures and adequate staffing with clear defined roles and processes including appropriate cleaning

- Use portable CXR in well ventilated rooms

- Use protective barriers to prevent patients from touching X-ray machine and to separate staff from patients

- Manage queuing of those presenting for screening by using markings on the ground to indicate required physical distancing and provide cloth or surgical masks

- Consider alternative screening algorithms that reduce the need for CXR such as initial screening using GeneXpert for TB, although these will be more expensive

Risk of spills when transporting sputum samples - Procedures and training of staff on safe handling and transportation of specimens

- Implement safety procedures for handling and transportation of specimens - triple packaging; spill kits

- Procedures and training of staff on safe handling and processing of specimens

- Implement safety procedures and infection control

Risk of transmission in laboratories due to specimen handling

- Support referral facilities if they have not yet implemented TB and COVID-19 triage and screening for all patients entering

$$
\text { care: }
$$

Health facility-based transmission of SARS-CoV-2 for TB patients required to attend health facilities for diagnosis and care services

Risk of missed diagnoses and loss to follow up if people are unwilling to travel to health facilities to access TB services

Patients may be unwilling or unable to use ACF services and other services

Insufficient supply of PPE to meet infection control needs

Unclear, inconsistent or incorrect messaging or information provided
- Implement home-based or community-based service models where possible (treatment initiation, treatment support, patient review)

- Provide TB patients with at least a month-long supply of treatment drugs so less frequent visits have to be made to the health centre for drug refills

- Use remote options to provide treatment support (phone calls, use of digital adherence tools) if in-person support is not possible

- Implement home-based or community-based service models where possible (treatment initiation, treatment support, patient review)

- Community engagement and education

- Collect qualitative feedback from patients and communities and adapt service design accordingly

- Extend the safe use of PPE items through cleaning, sterilisation and reuse

- Implement substitute methods where safe to do so: sterile booths, barriers, face shields over surgical masks

- Staff training as above

- Development of information, education and communication material (illustrated pamphlets) in local language

$\mathrm{PPE}=$ personal protective equipment; $\mathrm{ACF}$ = active case-finding; $\mathrm{CXR}=$ chest $\mathrm{X}$-ray.

large gatherings of people in close quarters while they await screening. Without physical distancing, such practices are conducive to transmission of SARS-CoV-2 to patients and staff. Fortunately, SARS-CoV-2 infection control measures can be readily integrated at testing sites and health facilities to establish COVID-19-safe TB ACF practices. Table 3 presents risks and challenges in TB ACF, alongside possible measures to mitigate risk.

\section{What other health services could be integrated into $T B$ ACF?}

TB ACF presents an opportunity for contact between individuals and health services that could also be used to reduce disruption of other health services due to COVID-19. Options include monitoring and referral for maternal and child health; supporting HIV and other chronic disease management (such as diabetes mellitus, hypertension); and immunisation coverage. In any given context 
the feasibility of integrating such services should be assessed, with consideration of how service integration might affect the uptake of the services.

\section{THE TB ACTIVE CASE-FINDING APPROACH ADAPTED FOR COVID-19 IN YOGYAKARTA}

In March 2020, we suspended our TB ACF activities in Yogyakarta, and evaluated the possibilities for safe resumption. We developed our framework of options for TB ACF adaptation by reviewing available literature on COVID-19, including international and Indonesian guidance on COVID-19 response. Using this information, the programme team - which includes global experts in TB programming - generated options for TB ACF that accorded with our essential criteria. We then used consensus-based methods to review the options and select a preferred approach.

Prior to resuming TB ACF, we monitored the COVID-19 response in Yogyakarta and the impact of the COVID-19 pandemic on TB services. In April 2020, our team determined that the criteria for resumption of TB ACF had been met. At the time when we resumed TB ACF in May 2020, only 236 confirmed COVID-19 cases had been reported in Yogyakarta. ${ }^{13}$ Even with the likelihood that this underestimated actual cases, this was considered a sign of a successful COVID-19 response. By this time, Yogyakarta Province had implemented COVID-19 contact tracing services, established infection control and COVID-19 screening at health centres, and had commenced scale-up of laboratory capacity for COVID-19 testing. The provincial and district health offices supported our programme's resumption of TB ACF using an adapted approach.

We elected to focus on TB ACF among household contacts of notified TB cases because they are a recognised high-risk population. ${ }^{14}$ We modified our contact investigation algorithm in several ways to manage the risk of SARS-CoV-2 transmission (Figures 1 and 2). To note, we combined symptom screening for TB and COVID-19.

We arrange visits to households of index cases, during which our team interviews household members and screens them for symptoms. Those with symptoms of upper respiratory infection or history of COVID-19 exposure are referred to the nearest health centre for COVID-19 investigation. Individuals with suspected COVID-19 are screened for TB only after completing diagnosis and management (including completion of any required quarantine) for COVID-19 in accordance with Indonesia's COVID-19 guidelines. Those with severe lower respiratory tract symptoms are admitted to hospital and investigated for both $\mathrm{TB}$ and COVID-19. Household members without suspected COVID-19 are referred to their nearest health centre on a designated date when our program's mobile chest X-ray (CXR) service is deployed at that health centre. This allows us to screen other outpatients attending the health centre. We collect spot sputum samples from those with CXR consistent with TB, cough that has lasted more than 2 weeks, or haemoptysis. Sputum samples are tested using Xpert $^{\circledR}$ MTB/RIF (Cepheid, Sunnyvale, CA, USA) at the district hospital. Persons with a positive Xpert result or a clinical diagno-

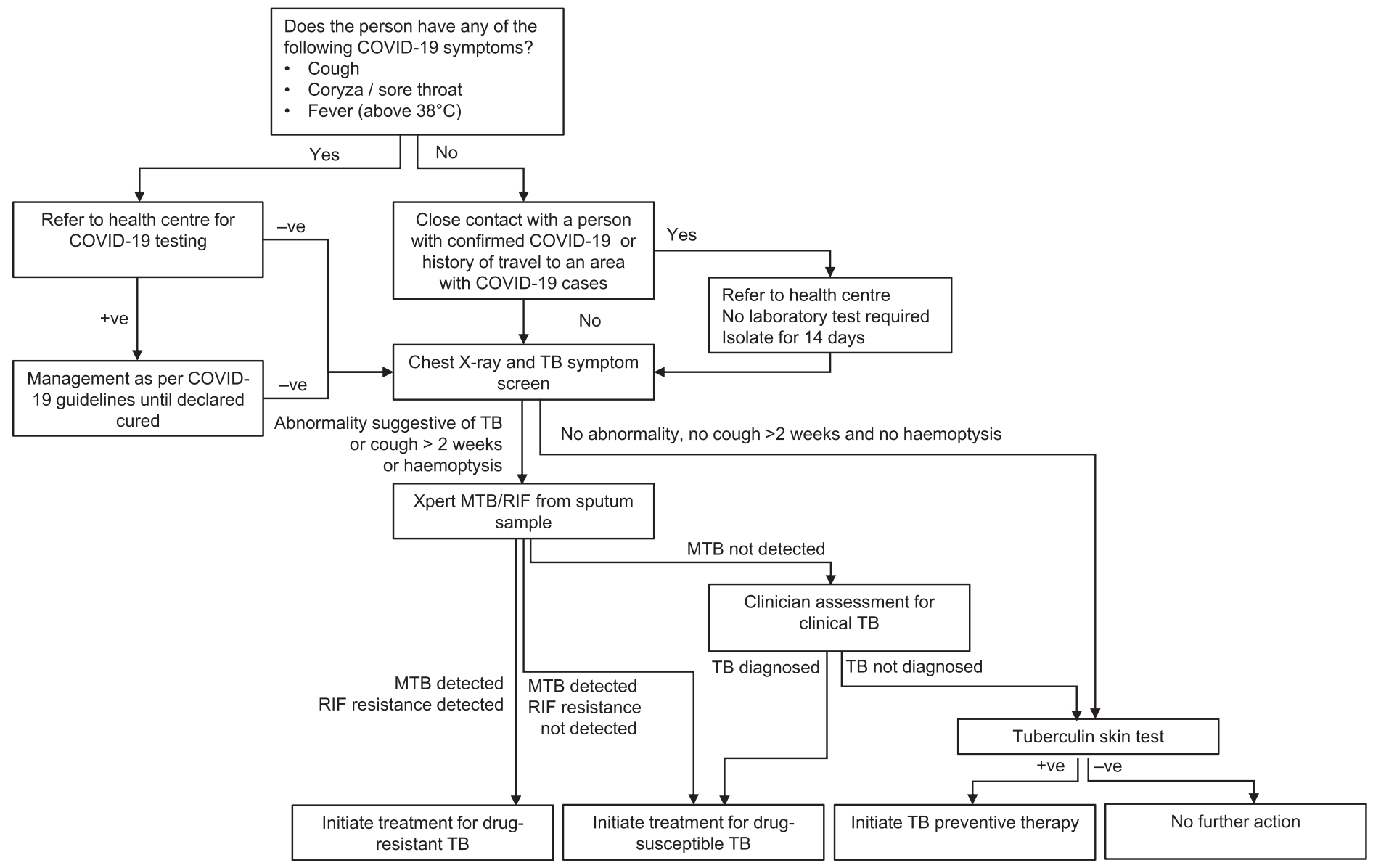

FICURE 1 The adapted TB active case-finding algorithm for persons aged $\geq 5$ years. $-\mathrm{ve}=$ negative; $+\mathrm{ve}=$ positive; MTB = M. tuberculosis; RIF = rifampicin. 


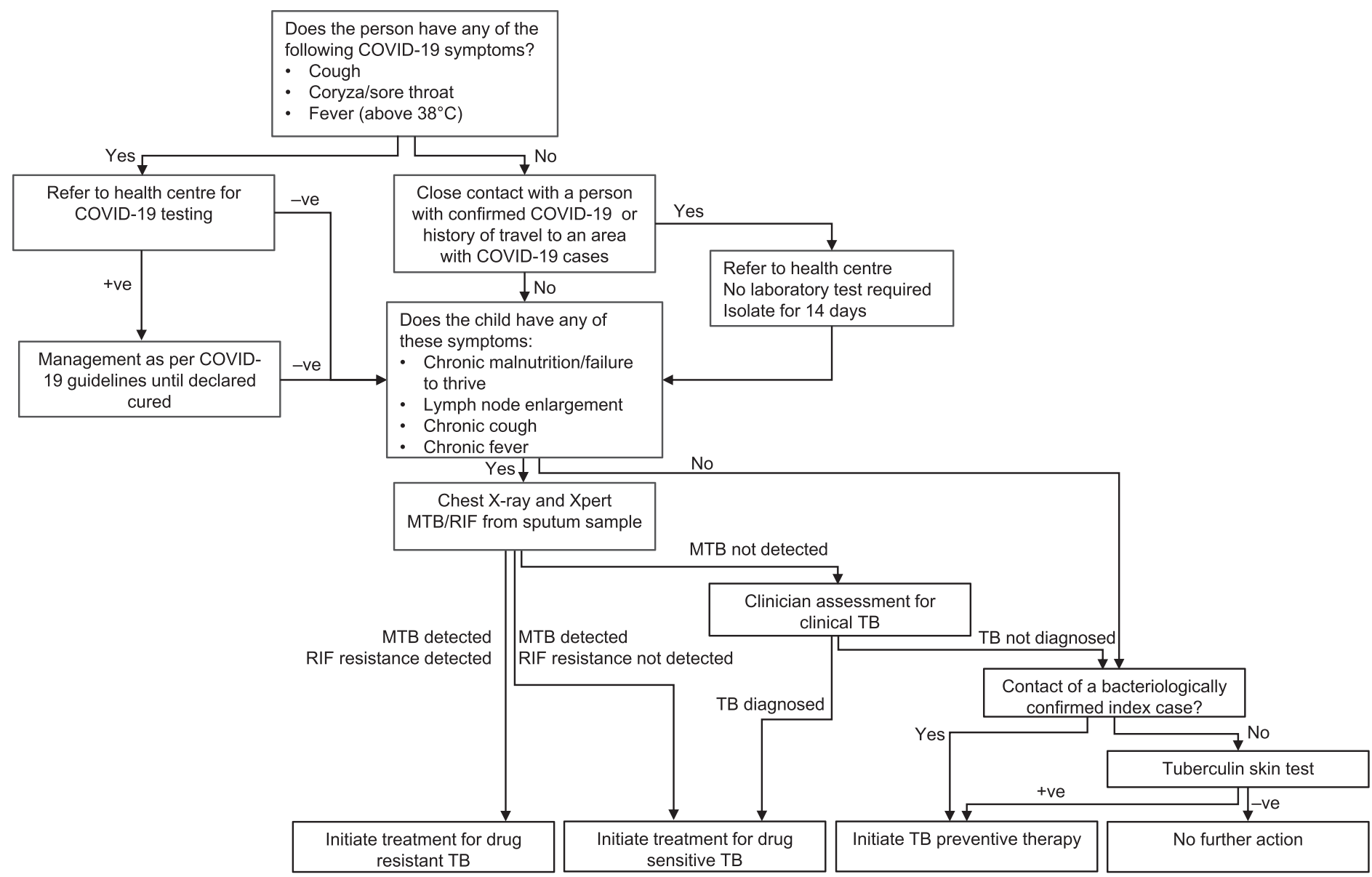

FIGURE 2 The adapted TB active case-finding algorithm for persons aged <5 years. $-\mathrm{ve}=$ negative; +ve = positive; MTB = M. tuberculosis; RIF $=$ rifampicin

sis of TB are referred to start treatment, either at a health centre or at home if unable to attend the health centre.

Preventive therapy using a 3-month regimen of daily rifampicin and isoniazid (3RH) is offered to household contacts once active TB has been ruled out (Figures 1 and 2). A regimen of 3 months of isoniazid and rifapentine (3HP) for individuals aged $\geq 5$ years will be used once it is locally available.

Infection control measures have been implemented to protect staff and persons being screened: physical distancing and the use of appropriate personal protective equipment (PPE) for staff when interviewing and collecting sputum; COVID-19 triage at the health centre; staff-patient and equipment-patient physical barriers in the CXR van; enhanced environmental cleaning of surfaces in patient areas (including the CXR van); ensuring good ventila- tion, physical distancing, hand hygiene and masks for persons being screened or awaiting care at the health centre; and regular COVID-19 testing for ACF staff.

We incorporated a cycle of design-implement-assess to test different approaches and adapted services based on feedback and results. Following the resumption of TB ACF among household contacts, the project has expanded the mobile van approach to include screening of populations living in slum areas.

\section{MONITORING REQUIREMENTS}

There is limited evidence on the best approaches for TB ACF during a COVID-19 outbreak. Consequently, we propose to monitor several key issues for our TB ACF approach (Table 4). It should

TABLE 4 Key issues that will be monitored during implementation

- Acceptability and uptake of the case-finding services and modalities

- Demand for COVID-19 testing

- Feasibility of environmental cleaning and use of natural or mechanical ventilation

- Adequacy of personal protective equipment supplies and access to hand washing and hand sanitiser

- Acceptability and utilisation of personal protective equipment among healthcare workers

- Loss to follow-up between initial screening of households and presentation at health facility

- Adverse impacts of the COVID-19 on socio-economic status of households that may affect ability to use services

- Preferred modalities for treatment initiation and treatment support

- Healthcare worker safety concerns

- Stigma of TB or COVID 19 for community members

- Throughput, yield and additional resources and costs 


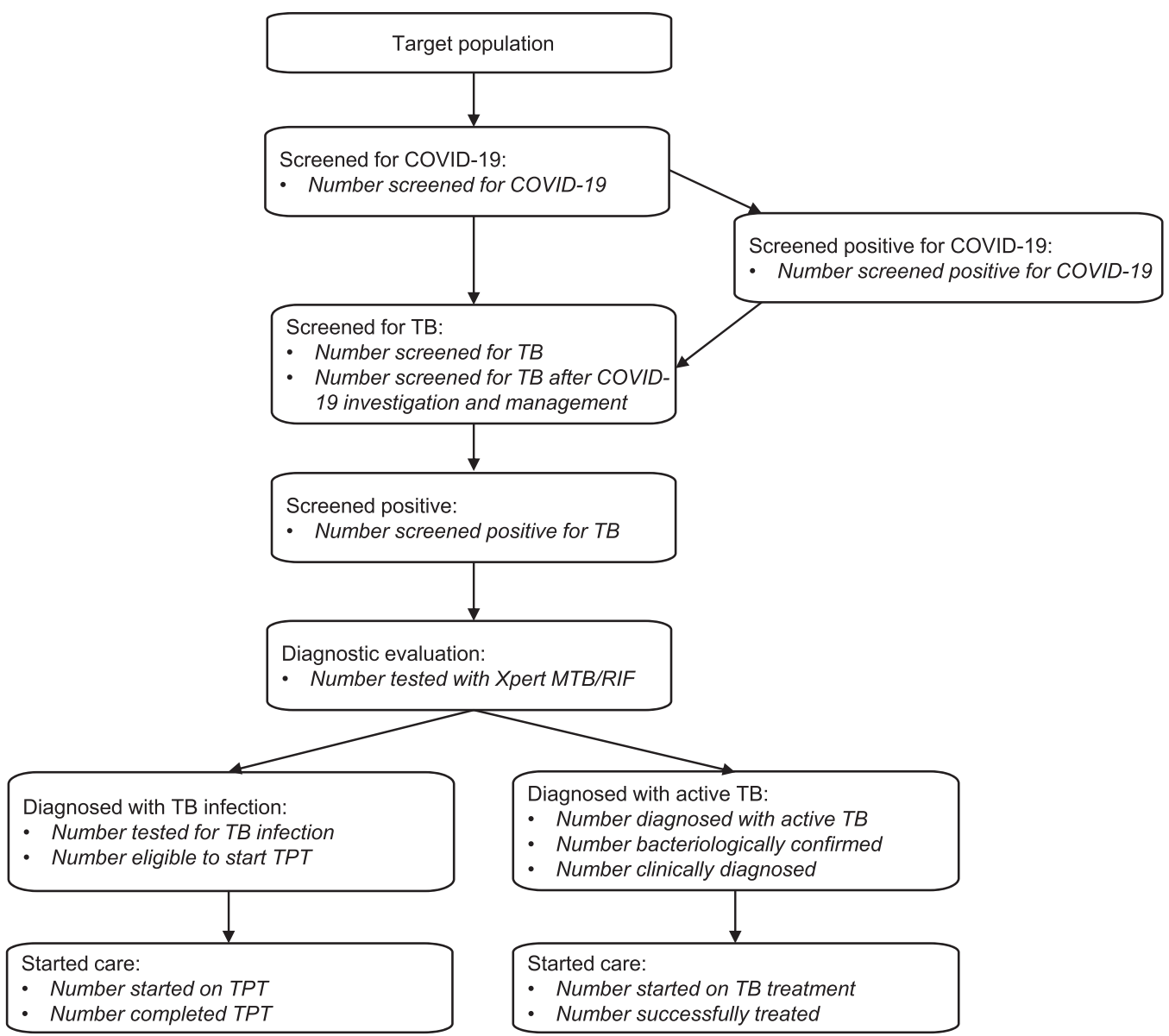

FIGURE 3 Proposed cascade for monitoring TB active case-finding with integrated COVID-19 screening. Indicators to be used for monitoring at each stage are in italics. TPT = TB preventive therapy.

be noted that the adaptations that are required for patient and staff safety result in additional procedures and reduced throughput of patients, raising questions about the operational feasibility of TB ACF. Documentation of the resulting additional resources and costs may be of interest to other programmes and settings. Finally, a central component of our monitoring will be the TB ACF cascade and yield, which we have adapted to capture the integration of COVID-19 screening into our activities (Figure 3).

\section{DISCUSSION}

Our framework for planning of adaptations to TB ACF represent early field experience in modifying TB case-finding activities so that they can continue during the COVID-19 pandemic and potentially mitigate its impact on TB burden. The checklist of essential criteria, options considered for adapting TB ACF and infection control measures were informed by the limited available evidence early in the pandemic. There is not yet evidence on the utility, safety or effectiveness of the adaptations that were ultimately implemented in Yogyakarta. Nonetheless, the process we undertook and the options we considered could be relevant and informative to other programmes in similar contexts of ongoing SARS-CoV-2 transmission.

As the pandemic situation evolves, it is important to reassess whether to continue TB ACF. This could be done by reassessing the situation against the essential criteria that we have proposed. In late 2020, for example, we temporarily suspended TB ACF due to increasing COVID-19 cases and when staff tested positive for COVID-19. It is possible that transmission occurred at our services despite good compliance with the infection control and prevention measures in place.

In this paper, we did not explore integration of TB case-finding into COVID-19 services as we did not implement this in Yogyakarta. Such integration also has potential to increase detection of TB during the COVID-19 pandemic, although substantial additional investment and resources could be required and the yield may be lower than for known at-risk populations for TB such as household contacts.

Controlling the spread of COVID-19 is currently a major public health priority and challenge. The integration of COVID-19 services with TB ACF activities is feasible, and could contribute to strengthening the public health response to both diseases. The multifaceted framework we used in Indonesia can be employed by other TB programmes seeking to resume TB ACF in the era of COVID-19.

\section{References}

1 Djalante R, et al. Review and analysis of current responses to COVID-19 in Indonesia: Period of January to March 2020. Prog Disaster Sci 2020; 6: 100091.

2 World Health Organization. Global tuberculosis report, 2020. Geneva, Swizerland: WHO, 2020. https://apps.who.int/iris/bitstream/handle/10665/3360 69/9789240013131-eng.pdf

3 World Health Organization. COVID-19: Operational guidance for maintaining essential health services during an outbreak: interim guidance, 25 March 2020. Geneva, Switzerland: WHO, 2020. 
4 Dye C, et al. Prospects for tuberculosis elimination. Annual Rev Public Health 2013; 34: 271-286.

5 Yuen CM, et al. Turning off the tap: Stopping tuberculosis transmission through active case-finding and prompt effective treatment. Lancet 2015; 386: 2334-2343.

6 Horváth B, et al. The social and economic impact of Covid-19 in the Asia-Pacific Region. Bangkok, Thailand: UNDP, 2020.

7 Hogan $\mathrm{AB}$, et al. Potential impact of the COVID-19 pandemic on HIV, tuberculosis, and malaria in low-income and middle-income countries : a modelling study. Lancet Glob Health 2020; 8: e1132-e1141.

8 Cilloni L, et al. The potential impact of the COVID-19 pandemic on the tuberculosis epidemic a modelling analysis. EClinicalMed 2020; 28: 100603.

9 Sands P. HIV, tuberculosis, and malaria: how can the impact of COVID-19 be minimised? Lancet Glob Health 2020; 8: e1102-e1103.
10 Saunders MJ, et al. Active and passive case-finding in tuberculosis-affected households in Peru: a 10-year prospective cohort study. Lancet Infect Dis 2019; 19: 519-528.

11 World Health Organization. Critical preparedness, readiness and response actions for COVID-19. Geneva, Switzerland: WHO, 2020.

12 Wacharapluesadee $S$, et al. Evaluating the efficiency of specimen pooling for PCR-based detection of COVID-19. J Med Virol 2020; 92: 21932199.

13 Peremintah Daerah, Daerah Istimewa Yogyakarta. Data Terkait COVID-19 di D.I. Yogyakarta, Indonesia: Peremintah Daerah, 2020. https://corona.jogjaprov.go.id/data-statistik Accessed August 2020.

14 Fox GJ, et al. Contact investigation for tuberculosis: a systematic review and meta-analysis. Eur Respir J 2013; 41: 140-156.
La pandémie de COVID-19 et les mesures de riposte incluant des confinements et une réorientation des services de santé ont perturbé les services de santé essentiels destinés aux autres maladies comme la $\mathrm{TB}$, le VIH et le paludisme. En ce qui concerne la TB, les réductions de la détection des cas dues à la pandémie de COVID-19 devrait entraîner une augmentation de la transmission, morbidité et mortalité de la TB. La recherche active des cas (ACF) de TB grâce à des approches communautaires est une stratégie potentielle visant à compenser pour les réductions de détection de la TB en écartant le besoin pour les patients de solliciter des soins dans un structure de santé. Plusieurs approches peuvent être utilisées pour réaliser l'ACF TB de façon sûre et de dépister des populations cibles désignées tout en gérant les risques de transmission du SARS-CoV-2 pour le personnel, les individus et la communauté. Nous présentons un cadre d'options et d'expériences d'adaptation des services TB ACF en réponse aux défis du COVID-19 dans notre programme à Yogyakarta, Indonésie. Les changements majeurs ont inclus une révision des priorités des populations cibles focalisée sur les contacts domiciliaires ; une réduction de la cadence de la recherche de cas; la mise en œuvre de mesures supplémentaires de lutte contre l'infection et de précautions; et l'intégration du dépistage de COVID-19 parmi ceux dépistés pour la TB. Notre approche pourrait informer d'autres programmes voulant adapter les services TB ACF afin d'atténuer I'impact négatif du COVID-19 sur la détection des cas de TB.
Public Health Action (PHA) welcomes the submission of articles on all aspects of operational research, including quality improvements, costbenefit analysis, ethics, equity, access to services and capacity building, with a focus on relevant areas of public health (e.g. infection control, nutrition, TB, HIV, vaccines, smoking, COVID-19, microbial resistance, outbreaks etc).
This is an Open Access article distributed under the terms of the Creative Commons Attribution License CC-BY 4.0 published by The Union (www.theunion.org) Contact: pha@theunion.org Information on PHA: http://www.theunion.org/what-we-do/journals/pha 


\section{University Library}

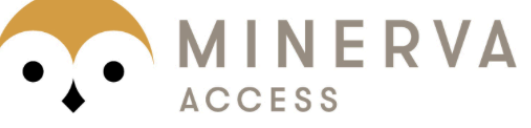

A gateway to Melbourne's research publications

Minerva Access is the Institutional Repository of The University of Melbourne

\section{Author/s:}

Chan, G;Triasih, R;Nababan, B;du Cros, P;Wilks, N;Main, S;Huang, GKL;Lin, D;Graham, SM;Majumdar, SS;Bakker, M;Khan, A;Khan, FA;Dwihardiani, B

Title:

Adapting active case-finding for TB during the COVID-19 pandemic in Yogyakarta, Indonesia

Date:

2021-06-21

Citation:

Chan, G., Triasih, R., Nababan, B., du Cros, P., Wilks, N., Main, S., Huang, G. K. L., Lin, D., Graham, S. M., Majumdar, S. S., Bakker, M., Khan, A., Khan, F. A. \& Dwihardiani, B. (2021). Adapting active case-finding for TB during the COVID-19 pandemic in Yogyakarta, Indonesia. Public Health Action, 11 (2), pp.41-49. https://doi.org/10.5588/pha.20.0071.

Persistent Link:

http://hdl.handle.net/11343/275641

License:

CC BY 